\title{
Investigating the CYP2B6 rs3745274 and rs3211371 Polymorphisms in Methadone-Responder and Non-Responder Addicts in Iran
}

\author{
Sara Sadat Aghabozorg Afjeh ${ }^{1,}$ Behzad Boshehri ${ }^{2,}$ Safar Hamednia ${ }^{3}$, \\ Asmaolhosna Amini ${ }^{4}$, Parisa Mashayekhi ${ }^{5}$ and Mir Davood Omrani ${ }^{1,6^{*}}$ \\ ${ }^{1}$ Department of Medical Genetics, Shahid Beheshti University of Medical Sciences, Tehran, Iran; \\ ${ }^{2}$ Department of Forensic Medicine and Toxicology, Urmia University of Medical Sciences, Urmia, Iran; \\ ${ }^{3}$ Department of Psychiatry, Urmia University of Medical Sciences, Urmia, Iran; ${ }^{4}$ Sara Medical Genetic \\ Laboratory, Tehran, Iran; ${ }^{5}$ Tajrish Research Center, Pasteur Institute of Iran, Tehran, Iran; ${ }^{6}$ Urogenital \\ Stem Cell Research Center, Shahid Beheshti University of Medical Sciences, Tehran, Iran
}

Received 10 December 2020; accepted 12 January 2021; published online 6 February 2021

\begin{abstract}
Background: Methadone therapy is a major protocol in opioid addiction cases in many health care systems. Population-based studies have shown that in addicted people, the genetic profile affects their response to methadone therapy. Therefore, this study designed to examine the frequency of two SNPs of the CYP2B6 gene ( $r$ 3745274 and rs3211371) in addicted cases in two methadone-responders and methadone non-responders groups. Methods: A total of 199 opioid-addicted individuals and 117 unaffected control subjects were genotyped for rs3745274 and rs3211371 polymorphisms of the CYP2B6 gene using the tetra-primer ARMS-PCR. Results: Results of this study revealed the significant association of rs3745274 GG $(p<0.001 ; \mathrm{OR}=0.027 ; 95 \% \mathrm{Cl}=0.14$ $0.49)$ and $\mathrm{GT}(p<0.001 ; \mathrm{OR}=4.04 ; 95 \% \mathrm{Cl}=2.26-7.21)$ genotypes with the risk of addiction in methadoneresponders. Also, a significant association between rs3745274 GG $(p<0.001 ; \mathrm{OR}=0.28 ; 95 \% \mathrm{Cl}=0.15-0.51)$ and $\mathrm{GT}(p<0.001 ; \mathrm{OR}=5.1 ; 95 \% \mathrm{Cl}=2.8-5.28)$ genotypes and addiction relapse was found in methadone nonresponders. Conclusion: Based on our findings, we can conclude that rs3745274 variant of CYP2B6 gene could serve as a potential biomarker, to evaluate the prognosis of addicted people fate under treatment with methadone. DOI: 10.52547/ibj.25.3.220
\end{abstract}

Keywords: Addiction, Biomarker, Methadone, Single-nucleotide polymorphism

Corresponding Authors: Mir Davood Omrani

Department of Medical Genetics, Faculty of Medicine, Shahid Beheshti University of Medical Sciences, Tehran, Iran; Tel.: (+98-21) 23872572;

E-mail: davood_omrani@yahoo.co.uk

\section{INTRODUCTION}

A ddictions, including SUDs, are frequently chronic, with a relapsing-remitting course. SUDs not only affect individuals but also impose many economic, cultural, and health burdens on society and consume a substantial portion of the health system resources every year worldwide ${ }^{[1]}$.
According to local reports, there are about 2-4 million substance abusers in $\operatorname{Iran}^{[2]}$. Among all substances, opium and opium residue are the most commonly used drugs in $\operatorname{Iran}^{[3]}$. At present, biological research has a significant role in reducing this social problem by expanding the range of information on addiction's origins and neurobiology and discovering new treatment strategies ${ }^{[4]}$. This level of study can provide a

List of Abbreviations:

95\% CI, 95\% confidence intervals; ARMS-PCR, amplification refractory mutation system-polymerase chain reaction; CYP, cytochrome p-450; OR, odd ratio; SNP, single-nucleotide polymorphism; SUD, substance use disorders, $\chi \mathbf{2}$, chi-square 
comprehensive view of the genetic effects, biological drug targets, neurotoxicity, and relevant signaling pathways that may lead to neuronal adaptation processes and subsequent uncontrolled substance use, withdrawal, temptation to consume, and relapse.

Given the irreparable harm of addiction and the complexities of treatment, finding genetic factors that can predict a person's susceptibility to addiction can reduce the number of addicts and speed up the treatment process for their withdrawal ${ }^{[5]}$. Twin studies have implied that genetic factors play a significant role in developing opioid addiction ${ }^{[6]}$. In fact, one of the main questions is why some people are more at risk of becoming addicted and abusing drugs than others. So far, many studies have been conducted to explore the genetic basis of addiction and have identified several candidate genes that their polymorphisms are associated with the development of addiction ${ }^{[4,7-11]}$. Besides, genes coding for metabolic enzymes, especially CYP enzymes, have been reported to be linked with response to methadone treatment in opioid addicts. In fact, liver CYP enzymes, particularly CYP3A4, CYP2B6, and CYP2D6, are responsible for the metabolism of many medications, such as methadone, which undergoes stereo-selective $\mathrm{N}$ demethylation ${ }^{[11,12]}$. Also, highly polymorphic CYP genes have shown inter-ethnic differences in allele frequencies ${ }^{[13]}$.

CYP2B6 SNPs have been displayed to be significantly related to higher (S)-methadone plasma levels ${ }^{[14-16]}$. Because of the functional similarity between methadone and opioids, genes affecting the methadone metabolism may influence the development or risk of opioid addiction ${ }^{[17]}$. To further extend previous studies on the relationship between $C Y P 2 B 6$ SNPs and the metabolism of methadone, we investigated the potential effects of two polymorphisms of CYP2B6 gene on the development of opioid addiction in a well-characterized sample, including two groups of patients. Group A took advantage of methadone with no co-medication, and group B were treated with adjuvant therapy, in addition to methadone, and did not have sufficient response to methadone treatment.

\section{MATERIALS AND METHODS}

\section{Sample Collection}

In this study, 99 opioid addicts on methadone maintenance therapy (group A) and 100 opioid addicts who were on adjuvant therapy with methadone, including gabapentin, risperidone, clonazepam, hydroxyzine, and other medications (group B), were selected as patient/case groups. All patients were diagnosed by the psychiatrists and clinical staff of the Ayatollah Taleghani Hospital of Urmia, West Azerbaijan Province, Iran. Besides, 117 healthy participants who were age- and sex-matched with the patient groups were selected with the following inclusion criteria: (1) they had not used any substance (except smoking) and (2) they had no psychiatric or neurological disorders or had not taken any drugs for medical conditions. Venous blood sample $(5 \mathrm{~mL})$ collected from participants and genomic DNA was isolated from peripheral blood leukocytes using the salting-out method according to the protocol described before $^{[18]}$. DNA concentrations were measured using a NanoDrop 2000c Spectrophotometer (Thermo Fisher Scientific; Wilmington, Delaware, USA).

\section{Tetra-primer ARMS-PCR}

Primers were designed using the Allele ID6 and Oligo7 software following the protocol explained by Ye et $a .^{[19]}$ and were synthesized by Pishgam Co. (Tehran, Iran). Primer sequences are presented in Table 1. Samples were genotyped for the CYP2B6 516G>T

Table 1. Primers used in the tetra-primer ARMS-PCR measurement method

\begin{tabular}{lllcccc}
\hline SNP & primers & Sequence $\left(\mathbf{5}^{\prime}->\mathbf{3}^{\prime}\right)$ & Length & Tm & GC $(\boldsymbol{\%})$ & Product size \\
\hline & F inner & GCAAAATACCCCCAACATACCAGAGCC & 27 & 65.94 & 51.85 & for C allele: 182 \\
rs3211371 & R inner & CCTTCAGCGGGGCAGGAATCA & 21 & 64.80 & 61.90 & for T allele: 231 \\
& & & & & & \\
& F outer & TATGCACCTGCCCTGTGCCCACA & 26 & 68.69 & 60.87 & two outer primers: 356 \\
& R outer & AGGGGAAGGAAGCTGGCTTGTA & 22 & 64.28 & 57.14 & \\
& & & & & & for G allele: 237 \\
rs3745274 & F inner & CTCATGGACCCCACCTTCCTCTTCTAG & 27 & 65.52 & 55.56 & for T allele: 288 \\
& R inner & AGCAGATGATGTTGGCGGTAATGAAA & 23 & 63.47 & 42.31 & two outer primers: 479 \\
& F outer & AGCCTCTCGGTCTGCCCATCTATAAAC & 27 & 65.80 & 51.85 & \\
& R outer & CAAGACAGGTCATCCTTTTCTCGTGTGT & 28 & 65.09 & 46.43 & \\
\hline
\end{tabular}

Tm, melting temperature 

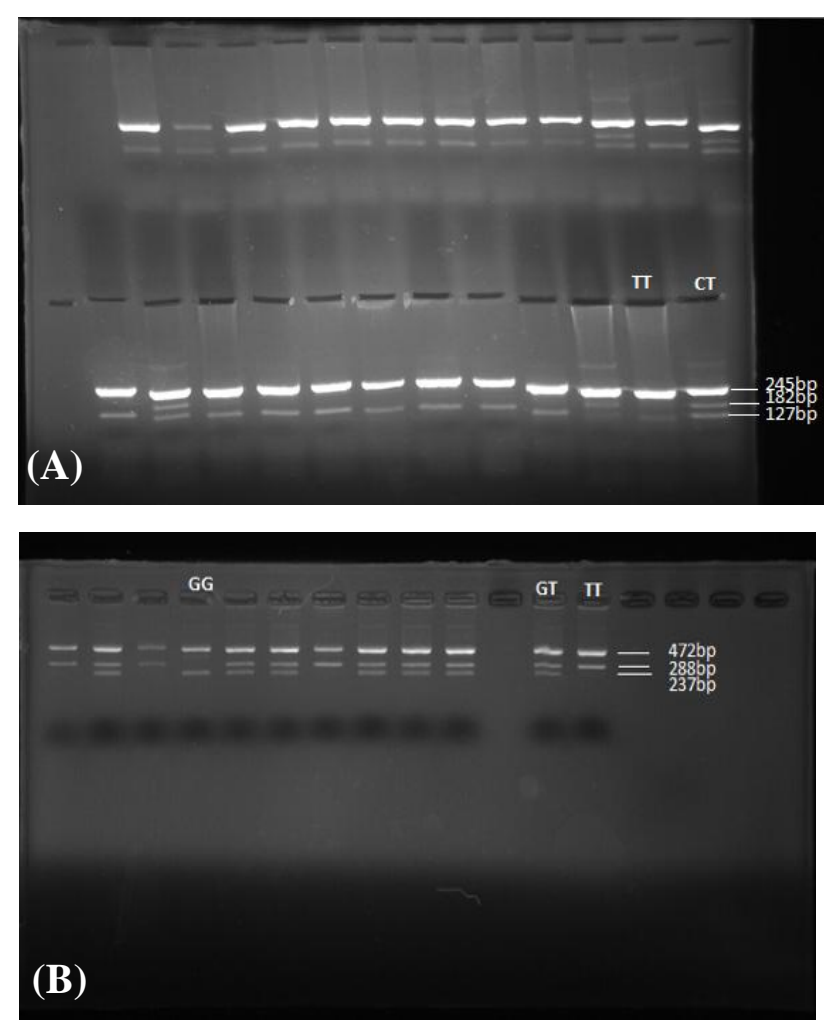

Fig. 1. Outer image of (A) rs3211371 and (B) rs3745274 gel electrophoresis

(rs3745274) and 1459C>T (rs3211371) SNP using tetra-primer ARMS-PCR. Each PCR reaction was carried out in a total volume of $10 \mu \mathrm{l}$ containing $30 \mathrm{ng}$ of the extracted DNA, and 1 pmol of each inner and outer primer (Table 1), $200 \mu \mathrm{M}$ of dNTP, $\mathrm{MgCl}_{2}$, and $0.5 \mathrm{U}$ Taq polymerase (Life Technologies, USA). PCR was performed as one cycle of $95^{\circ} \mathrm{C}$ for $5 \mathrm{~min}$, followed by 30 cycles of $95^{\circ} \mathrm{C}$ for $40 \mathrm{~s}, 62^{\circ} \mathrm{C}$ for $35 \mathrm{~s}$ (according to the annealing temperatures for different PCRs shown in Table 1), $72{ }^{\circ} \mathrm{C}$ for $30 \mathrm{~s}$, and an additional 10 -min extension at $72{ }^{\circ} \mathrm{C}$. PCR products were analyzed by $1.5 \%$ agarose gel electrophoresis in Tris/Borate/EDTA $1 \times$ buffer.

\section{Statistical analysis}

The Microsoft Excel 2019 and SPSS 24.0 statistical software (SPSS, Chicago, IL) were applied for the statistical analysis of the data of this case-control study. Both patients and control groups were analyzed using $\chi 2$ test to determine the fitness to the HardyWeinberg equilibrium. The $\chi 2$ test was also used for comparing genotype and allelic frequencies between the methadone-dependent subjects and controls. The ORs and $95 \%$ CI were calculated for this comparison. In all analyses, $p$ values were two-sided and statistically significant if less than 0.05 .

\section{Ethics statement}

The above-mentioned sampling protocols were approved by the Ethics Committee of Shahid Beheshti University of Medical Sciences, Tehran, Iran (ethical code: IR.SBMU.MSP.REC.1398.213). Informed consents were signed by all participants.

\section{RESULTS}

The outer images of genotyping of rs3211371 and rs3745274 are shown in Figure 1. Allele frequencies and genotyping of the both polymorphisms in addicted subjects and unaffected control group were determined using the tetra-primer ARMS-PCR (Tables 2 and 3). As represented in Table 2, in the addicted group, the frequencies of the $\mathrm{G}$ and $\mathrm{T}$ alleles of rs3745274 polymorphism were $58.5 \%$ and $41.5 \%$, while those of $\mathrm{C}$ and $\mathrm{T}$ alleles were $91.3 \%$ and $8.7 \%$, respectively for rs3211371 polymorphism.

Genotype distribution among the addicted people (group A and B) as well as unaffected controls is shown in Table 3. Genotype frequency of the rs3745274 polymorphism in group A in comparison to the control subjects was $20.3 \%$ vs. $48.7 \%$ for the GG homozygous, $6 \%$ vs. $10.2 \%$ for the TT homozygous, and $73.7 \%$ vs. $41 \%$ for heterozygous GT. Analysis showed no significant association between rs3211371 polymorphism and the risk of relapse of addiction. As depicted in Table 4, there was a significant association of rs3745274 GG $\left(\chi^{2}=19.008 ; p<0.001\right.$; OR = 0.027; $95 \% \mathrm{CI}=0.14-0.49)$ and GT $\left(\chi^{2}=23.290\right.$; $p<0.001 ; \mathrm{OR}=4.04 ; 95 \% \mathrm{CI}=2.26-7.21)$ genotypes with the risk of addiction in methadone-responders in the studied population. Moreover, rs3745274 genotype frequencies in group B compared to the control group were $21 \%$ vs. $48.7 \%$ for the GG genotype, $1 \%$ vs. $10.2 \%$ for the TT genotype, and $78 \%$ vs. $41 \%$ for GT genotype. There was also a significant association of rs3745274 GG $\left(\chi^{2}=17.991 ; p<0.001 ;\right.$ OR $=0.28$; $95 \% \mathrm{CI}=0.15-0.51)$ and $\mathrm{GT}\left(\chi^{2}=30.271 ; p<0.001\right.$; $\mathrm{OR}=5.1 ; 95 \% \mathrm{CI}=2.8-5.28$; Table 4$)$ genotypes with the risk of addiction in methadone non-responders in Iranian population.

Table 2. Allele frequencies in the addicted subjects and unaffected controls

\begin{tabular}{cccc}
\hline SNP & Allele & $\begin{array}{c}\text { Addicted } \\
\text { subject no. }(\%)\end{array}$ & $\begin{array}{c}\text { Control } \\
\text { No. }(\%)\end{array}$ \\
\hline \multirow{2}{*}{ rs3745274 } & $\mathrm{G}$ & $233(58.5)$ & $162(69.2)$ \\
& $\mathrm{T}$ & $165(41.5)$ & $72(30.8)$ \\
rs3211371 & $\mathrm{C}$ & $336(91.3)$ & $219(93.5)$ \\
& $\mathrm{T}$ & $32(8.7)$ & $15(6.5)$ \\
\hline
\end{tabular}


Table 3. Genotype distribution among the addicted cases and unaffected controls

\begin{tabular}{ccccc}
\hline SNP & Genotype & $\begin{array}{c}\text { Group A } \\
\text { no. (\%) }\end{array}$ & $\begin{array}{c}\text { Group B } \\
\text { no. (\%) }\end{array}$ & $\begin{array}{c}\text { Controls } \\
\text { no. (\%) }\end{array}$ \\
\hline \multirow{3}{*}{ rs3745274 } & GG & $20(20.3)$ & $21(21)$ & $57(48.7)$ \\
& GT & $73(73.7)$ & $78(78)$ & $48(41)$ \\
& TT & $6(6)$ & $1(1)$ & $12(10.2)$ \\
rs3211371 & & & & \\
& CC & $85(85.8)$ & $73(73)$ & $103(88)$ \\
& CT & $14(14.2)$ & $16(16)$ & $13(11.2)$ \\
& TT & $0(0)$ & $1(1)$ & $1(0.8)$ \\
\hline
\end{tabular}

\section{DISCUSSION}

The prevalence of opioid addiction has increased to epidemic levels; however, therapeutic interventions remain limited. Despite the effectiveness of methadone treatment, there is always a risk of relapse ${ }^{[20]}$. Based on reports, about $46 \%$ of addicted patients continue to use opioids during or after the methadone treatment. It is not yet clear how interactions between genes, environment, and drugs can affect the recurrence of addiction $^{[21]}$. Recently, numerous studies have demonstrated that CYP2B6 gene is involved in methadone metabolism and clearance and plasma concentrations ${ }^{[22-24]}$. It has also been reported that some variations of $C Y P 2 B 6$ could help to identify subjects at risk for methadone toxicity or relapse of addiction $^{[25-27]}$.

This study aimed to discover the association of rs3745274 and rs3211371 SNPs of the CYP2B6 gene with opioid addiction relapse. For further understanding the role of these SNPs, samples of addicted patients were divided into two groups based on the response of individuals to methadone treatment. Group A included opioid-addicted patients who remained on methadone maintenance therapy, and group B included opioid-addicted patients who did not show appropriate response to methadone therapy and, therefore, were under adjuvant therapy. The rs3745274 is a missense polymorphism within the $C Y P 2 B 6$ gene and has been widely reported to be involved in various responses to some medications, including methadone ${ }^{[28-30]}$.

Results of this study showed that GG and GT genotypes of rs3745274 are significantly associated with the risk of addiction in both group A and group B of addicted patients. This result highlights the possible role of this variant of $C Y P 2 B 6$ gene in the effectiveness of medications in opioid-addicted patients. Given the importance of this polymorphism in drug metabolism, it is not unreasonable to expect that it can affect the effectiveness of various substances and cause the recurrence of addiction in patients under treatment. Our

Table 4. Genotypic model analysis of the association of rs3745274 polymorphism with groups A and B

\begin{tabular}{lccccc}
\hline \multirow{2}{*}{ Subjects } & GG & Genotypes & \multirow{2}{*}{ Total } & p value \\
\cline { 2 - 4 } Group A & $20(20.2 \%)$ & $73(73.7 \%)$ & $6(6 \%)$ & 99 & $<0.001$ \\
Control & $57(48.7 \%)$ & $48(41 . \%)$ & $12(10.3 \%)$ & 117 & $<0.001$ \\
Total & 77 & 121 & 18 & 216 & \\
$\chi 2$ & 19.008 & 23.290 & & & \\
OR & 0.027 & 4.04 & & & \\
$95 \%$ CI & & & & & \\
Lower bound & 0.14 & 2.26 & & & \\
Upper bound & 0.49 & 7.21 & & 100 & $<0.001$ \\
& & & & 217 & $<0.001$ \\
Group B & $21(21 \%)$ & $78(78 \%)$ & $1(1 \%)$ & & \\
Control & $57(48.7 \%)$ & $48(41 \%)$ & $12(10.2 \%)$ & & \\
Total & 78 & 126 & 13 & & \\
$\chi 2$ & 17.991 & 30.271 & & & \\
OR & 0.28 & 5.1 & & & \\
$95 \%$ CI & & & & & \\
Lower bound & 0.15 & 2.8 & & & \\
Upper bound & 0.51 & 5.28 & & & \\
\hline
\end{tabular}

*Pearson $\chi 2$ test 
results also indicated no significant association between rs3211371 SNP and the risk of opioid addiction. This SNP is a missense polymorphism within the $C Y P 2 B 6$ gene that has previously been reported in association with methadone metabolism ${ }^{[31]}$. This lack of association may be due to the small number of samples and the limitations of the study.

According to the results of this study, rs3745274 variant of $C Y P 2 B 6$ could be considered as a potential biomarker for evaluating the prognosis of addicted patients fate under treatment with methadone. Additional studies are also necessary to find other relevant variants of $C Y P 2 B 6$ gene and understand the underlying mechanism by which the rs3745274 SNP influences the susceptibility to opioid relapse.

\section{ACKNOWLEDGEMENTS}

We thank Urmia's Ayatollah Taleghani Hospital staff who kindly helped with our sample collection and provided the data necessary for our analysis. Funding for this study was provided by Shahid Beheshti University of Medical Sciences (SBMU), Tehran Iran. The SBMU had no further role in the study design, in the collection, analysis and interpretation of data, in the writing of the report, and in the decision to submit the paper for publication.

CONFLICT OF INTEREST. None declared.

\section{REFERENCES}

1. Degenhardt L, Whiteford HA, Ferrari AJ, Baxter AJ, Charlson FJ, Hall WD, Freedman G, Burstein R, Johns N, Engell RE, Flaxman A, Murray CJL, Vos T. Global burden of disease attributable to illicit drug use and dependence: findings from the Global Burden of Disease Study 2010. Lancet 2013; 382(9904): 15641574.

2. Saberi Zafarghandi MB, Jadidi M, Khalili N. Iran's activities on prevention, treatment and harm reduction of drug abuse. International journal of high risk behaviors and addiction 2015; 4(4): e22863.

3. Ghane T, Zamani N, Hassanian-Moghaddam $\mathrm{H}$, Beyrami A, Noroozi A. Lead poisoning outbreak among opium users in the Islamic Republic of Iran, 2016-2017. Bulletin of the World Health Organization 2018; 96(3): 165-172.

4. Bevilacqua L, Goldman D. Genes and addictions. Clinical pharmacology therapeutics 2009; 85(4): 359361.

5. Sinha R. Chronic stress, drug use, and vulnerability to addiction. Annals of the New York academy of sciences 2008; 1141: 105-130.
6. Berrettini W. A brief review of the genetics and pharmacogenetics of opioid use disorders. Dialogues in clinical neuroscience 2017; 19(3): 229-236.

7. Kendler KS, Jacobson KC, Gardner CO, Gillespie N, Aggen SA, Prescott CA. Creating a social world: A developmental twin study of peer-group deviance. Archives of general psychiatry 2007; 64(8): 958-965.

8. Thorgeirsson TE, Geller F, Sulem P, Rafnar T, Wiste A, Magnusson KP, Manolescu A, Thorleifsson G, Stefansson H, Ingason A, Stacey SN, Bergthorsson JT, Thorlacius S, Gudmundsson J, Jonsson T, Jakobsdottir M, Saemundsdottir J, Olafsdottir O, Gudmundsson LJ, Bjornsdottir G, Kristjansson K, Skuladottir H, Isaksson HJ, Gudbjartsson T, Jones GT, Mueller T, Gottsäter A, Flex A, Aben KKH, de Vegt F, Mulders PFA, Isla D, Vidal MJ, Asin L, Saez B, Murillo L, Blondal T, Kolbeinsson H, Stefansson JG, Hansdottir I, Runarsdottir V, Pola R, Lindblad B, van Rij AM, Dieplinger B, Haltmayer M, Mayordomo JI, Kiemeney LA, Matthiasson SE, Oskarsson $\mathrm{H}$, Tyrfingsson $\mathrm{T}$, Gudbjartsson DF, Gulcher JR, Jonsson S, Thorsteinsdottir U, Kong A, Stefansson K. A variant associated with nicotine dependence, lung cancer and peripheral arterial disease. Nature 2008. 452(7187):638642.

9. Tobacco and Genetics Consortium. Genome-wide meta-analyses identify multiple loci associated with smoking behavior. Nature Genetics 2010; 42(5): 441447.

10. Thorgeirsson TE, Gudbjartsson DF, Surakka I, Vink JM, Amin N, Geller F, Sulem P, Rafnar T, Esko T, Walter S, Gieger C, Rawal R, Mangino M, Prokopenko I, Mägi R, Keskitalo K, Gudjonsdottir IH, Gretarsdottir S, Stefansson H, Thompson JR, Aulchenko YS, Nelis M, Aben KK, den Heijer M, Dirksen A, Ashraf H, Soranzo N, Valdes AM, Steves C, Uitterlinden AG, Hofman A, Tönjes A, Kovacs P, Hottenga JJ, Willemsen G, Vogelzangs N, Döring A, Dahmen N, Nitz B, Pergadia ML, Saez B, De Diego V, Lezcano V, Garcia-Prats MD, Ripatti S, Perola M, Kettunen J, Hartikainen AL, Pouta A, Laitinen J, Isohanni M, HueiYi S, Allen M, Krestyaninova M, Hall AS, Jones GT, van Rij AM, Mueller T, Dieplinger B, Haltmayer M, Jonsson S, Matthiasson SE, Oskarsson H, Tyrfingsson T, Kiemeney LA, Mayordomo JI, Lindholt JS, Pedersen JH, Franklin WA, Wolf H, Montgomery GW, Heath AC, Martin NG, Madden PA, Giegling I, Rujescu D, Järvelin MR, Salomaa V, Stumvoll M, Spector TD, Wichmann HE, Metspalu A, Samani NJ, Penninx BW, Oostra BA, Boomsma DI, Tiemeier H, van Duijn CM, Kaprio J, Gulcher JR; ENGAGE Consortium, McCarthy MI, Peltonen L, Thorsteinsdottir U, Stefansson K. Sequence variants at CHRNB3-CHRNA6 and CYP2A6 affect smoking behavior. Nature genetics 2010; 42(5): 448-453.

11. Bart G, Heilig M, LaForge KS, Pollak L, Leal SM, Ott J, Kreek MJ. Substantial attributable risk related to a functional mu-opioid receptor gene polymorphism in association with heroin addiction in central Sweden. Molecular psychiatry 2004; 9(6): 547-549. 
12. Kreek MJ, Levran O, Reed B, Schlussman SD, Zhou Y, Butelman ER. Opiate addiction and cocaine addiction: underlying molecular neurobiology and genetics. Journal of clinical investigation 2012; 122(10): 3387 3393.

13. Maréchal JD, Kemp CA, Roberts GC, Paine MJ, Wolf $\mathrm{CR}$, Sutcliffe MJ. Insights into drug metabolism by cytochromes $\mathrm{P}_{450}$ from modelling studies of CYP2D6drug interactions. British journal of pharmacology 2008; 153 Suppl 1(Suppl 1): S82-S89.

14. Levran O, Peles E, Hamon S, Randesi M, Adelson M, Kreek MJ. CYP2B6 SNPs are associated with methadone dose required for effective treatment of opioid addiction. Addiction biology 2013; 18(4): 709716.

15. Zhou SF, Liu JP, Chowbay B. Polymorphism of human cytochrome P450 enzymes and its clinical impact. Drug metabolism reviews 2009; 41(2): 89-295.

16. Somogyi AA, Barratt DT, Ali RL, Coller JK. Pharmacogenomics of methadone maintenance treatment. Pharmacogenomics 2014; 15(7): 1007-1027.

17. National Center for Biotechnology Information. PubChem Compound Summary for CID 4095, Methadone. Reterieved from: https://pubchem.ncbi.nlm. nih.gov/compound/Methadone.

18. Miller SA, Dykes DD, Polesky HF. A simple salting out procedure for extracting DNA from human nucleated cells. Nucleic acids research 1988; 16(3):1215.

19. Ye S, Dhillon S, Ke X, Collins AR, Day IN. An efficient procedure for genotyping single nucleotide polymorphisms. Nucleic acids research 2001; 29(17): E88.

20. Bart G. Maintenance medication for opiate addiction: the foundation of recovery. Journal of addictive diseases 2012; 31(3): 207-225.

21. Naji L, Dennis BB, Bawor M, Plater C, Pare G, Worster A, Varenbut M, Daiter J, Marsh DC, Desai D, Thabane L, Samaan Z. A prospective study to investigate predictors of relapse among patients with opioid use disorder treated with methadone. Substance abuse 2016; 10: $9-18$

22. Victorri-Vigneau C, Verstuyft C, Bouquié R, Laforgue EJ, Hardouin JB, Leboucher J, Le Geay B, Dano C, Challet-Bouju G, Grall-Bronnec M. Relevance of CYP2B6 and CYP2D6 genotypes to methadone pharmacokinetics and response in the OPAL study. British journal of clinical pharmacology 2019; 85(7): 1538-1543.
23. Talal AH, Ding Y, Venuto CS, Chakan LM, McLeod A, Dharia A, Morse GD, Brown LS, Markatou M, Kharasch ED. Toward precision prescribing for methadone: Determinants of methadone deposition. PLoS one 2020; 15(4): e0231467.

24. Chiang YC, Wang RY, Huang CL, Chen SH, Ho WJ, Lane HY, Ho IK, Yang HT, Ma WL. Reduced dosing and liability in methadone maintenance treatment by targeting oestrogen signal for morphine addiction. Journal of vellular and molecular medicine 2017; 21(12): 3552-3564.

25. Kharasch ED, Regina KJ, Blood J, Friedel C. Methadone pharmacogenetics: CYP2B6 polymorphisms determine plasma concentrations, clearance, and metabolism. Anesthesiology 2015; 123(5):1142-1153.

26. Gadel S, Friedel C, Kharasch ED. Differences in methadone metabolism by CYP2B6 variants. Drug metabolism and disposition 2015; 43(7): 994-1001.

27. Amunugama HT, Zhang H, Hollenberg PF. Mechanismbased inactivation of cytochrome P450 2B6 by methadone through destruction of prosthetic heme. Drug metabolism and disposition 2012; 40(9): 1765-1770.

28. Zubiaur P, Saiz-Rodríguez M, Ochoa D, Belmonte C, Román M, Mejía G, Martín-Vilchez S, Abad-Santos F. Influence of CYP2B6 activity score on the pharmacokinetics and safety of single dose efavirenz in healthy volunteers. Pharmacogenomics 2020. 20(2): 235-245.

29. Crocco P, Montesanto A, Dato S, Geracitano S, Iannone F, Passarino G, Rose G. Inter-individual variability in xenobiotic-metabolizing enzymes: implications for human aging and longevity. Genes (Basel) 201; 10(5): 403.

30. Chang JL, Lee SA, Tsai AC, Musinguzi N, Muzoora C, Bwana B, Boum Y 2nd, Haberer JE, Hunt PW, Martin J, Bangsberg DR, Kroetz DL, Siedner MJ. CYP2B6 genetic polymorphisms, depression, and viral suppression in adults living with HIV initiating Efavirenz-Containing Antiretroviral Therapy Regimens in Uganda: pooled analysis of two prospective studies. AIDS research human retroviruses 2018; 34(11):982992.

31. Ahmad T, Sabet S, Primerano DA, Richards-Waugh LL, Rankin GO. Tell-Tale SNPs: The role of CYP2B6 in methadone fatalities. Journal of analytical toxicology 2017; 41(4): 325-333 